\title{
Avaliação da degradação de estruturas de concreto: Estudo de caso em um supermercado no Bairro do Rio Vermelho - Salvador/BA
}

\author{
P.V.G. FREITAS ${ }^{1 *}$; P.C. NUNES, ${ }^{2}$; A. R. A. OMORE ${ }^{3}$, M. A. MACHADO ${ }^{3}$, V. A. COELHO ${ }^{4}$; \\ F. G.S. SILVA ${ }^{5}$ \\ *Autor de Contacto: priscilav@fieb,org.br \\ ${ }^{1}$ Área de construção civil, SENAI CIMATEC, Salvador, Brasil \\ ${ }^{2}$ Pós-Graduanda em Engenharia de Avaliações e Perícias, UNIJORGE, Salvador, Brasil \\ ${ }^{3}$ Graduado(a) em Engenharia Civil, Escola Politécnica, Universidade Federal da Bahia, Salvador, Brasil \\ ${ }^{4}$ PPEC, Escola Politécnica, Universidade Federal da Bahia, Salvador, Brasil \\ ${ }^{5}$ Departamento de Construção e Estruturas, Universidade Federal da Bahia, Salvador, Brasil
}

\begin{abstract}
RESUMO
A degradação de estruturas em edificações próximas a áreas marinhas é um fato comum em cidades litorâneas. Muitas vezes a avaliação da extensão dos danos se torna uma atividade complexa, demandando a utilização de um método adequado para este fim. Este estudo propõe a utilização do modelo GDE/UnB, proposto por Fonseca, para avaliação de uma edificação situada próxima ao mar na cidade de Salvador - BA. Desta forma, a metodologia utilizada foi: 1)Seleção da edificação; 2)Vistoria in loco; 3)Ensaios e inspeção; 4)Aplicação da Metodologia; 5)Considerações. Os resultados obtidos apontaram o alto grau de comprometimento edificação, não apenas com a inspeção visual, mas também com ferramentas determinísticas, como a metodologia GDE/UnB. A limitação da pesquisa concentra-se na quantidade de peças estruturais investigadas, pois a avaliação foi amostral. A pesquisa revelou os pontos de maior criticidade, bem como as ações que imediatamente deverão ser realizadas em função do grau de deterioração da estrutura.
\end{abstract}

Palavras chave: Degradação; Inspeção; Metodologia GDE/UnB 


\title{
Evaluation of the degradation of concrete structures: a case study in a market in the district of the Rio Vermelho - Salvador/BA
}

\begin{abstract}
The degradation of structures in buildings close to marine areas is a common fact in coastal cities. This study demonstrates that in building inspections where the degree of structures deterioration is evaluated, it can be more assertive if performed in association with objective techniques, such as the GDE/UnB model, proposed by Fonseca. Thus, the methodology of the article was: 1) Selection of the building; 2) On-site inspection; 3) Tests and inspection; 4) Application of the Methodology; 5) Considerations. The results obtained showed the high degree of commitment to the building, not only with visual inspection, but also with deterministic tools, such as the GDE/UnB Methodology. The limitation of the research focuses on the number of structural parts investigated, the evaluation was on a sample basis. The research revealed the most critical points, as well as the actions that should be taken immediately due to the Degree of deterioration of the structure found.
\end{abstract}

Keywords: Degradation; Inspection; Methodology GDE/UnB

\section{Evaluación de la degradación de estructuras de hormigón: un estudio de caso en un supermercado en Bairro do Rio Vermelho - Salvador / BA}

\begin{abstract}
RESUMEN
La degradación de estructuras en edificios cercanos a áreas marinas es un hecho común en las ciudades costeras. Este trabajo demuestra que en las inspecciones de edificaciones donde se evalúa el grado de deterioro de las estructuras, puede ser más asertivo si se realiza en asociación con técnicas objetivas, como el modelo GDE/UnB, propuesto por Fonseca. Así, la metodología del artículo fue: 1) Selección del edificio; 2) Inspección in situ; 3) Pruebas e inspección; 4) Aplicación de la Metodología; 5) Consideraciones. Los resultados obtenidos evidenciaron el alto grado de degradacion edificación, no solo con la inspección visual, sino también con herramientas deterministas, como la Metodología GDE / UnB. La limitación de la investigación se centra en el número de piezas estructurales investigadas, la evaluación se realizó sobre una base de muestra. La investigación reveló los puntos más críticos, así como las acciones que deben tomarse de manera inmediata debido al Grado de deterioro de la estructura.
\end{abstract}

Palabras clave: Degradación; Inspecion; Metodologia GDE/UnB 


\section{INTRODUÇÃO}

As edificações apresentam uma característica que as diferencia de outros produtos: elas são construídas para atender a seus usuários durante muito tempo e devem apresentar condições adequadas (ABNT, 2012). Pensando na importância das edificações em nossas vidas, é fundamental que as manutenções sejam realizadas de maneira correta. $O$ descuido com relação às manutenções geralmente reduz a durabilidade e o tempo de vida útil projetado (VUP), bem como seu valor de mercado. Dessa maneira, pode-se observar que as atividades de manutenções devem ser previstas de maneira a garantir os níveis de funcionalidade adequada dos sistemas (SILVA, 2014). A NBR 6118 (ABNT, 2014) define a durabilidade como a capacidade da estrutura em resistir às influências ambientais previstas e definidas em conjunto pelo autor do projeto estrutural e pelo contratante no início dos trabalhos de elaboração do projeto.

O sistema estrutural deve ser priorizado nas inspeções periódicas de uma edificação, pois seu comprometimento geralmente incorre em alto custo com manutenção e pode custar a vida de pessoas. As estruturas de concreto armado podem sofrer degradações ao longo do tempo, principalmente considerando os fatores relacionados às condições ambientais, como ventos, sol, chuva e névoa salina. Como fatores secundários observa-se a ausência de programas de manutenção preventiva nas edificações. De acordo com Castro (1994), a vida útil da estrutura depende, substancialmente, de níveis adequados de manutenção. Para manter a capacidade funcional durante a vida útil prevista em projeto, sem os sinais de desgaste do edifício, devem se realizar as intervenções periódicas de manutenção e conservação (BAUER et al, 2011).

A principal manifestação patológica observada nas estruturas de concreto é a corrosão das armaduras. De acordo com Vilasboas (2013), ela abrange, principalmente, os processos de deterioração que incidem nas barras e nos fios de aço destinados às armaduras das estruturas. Em alguns casos, há degradação da própria pasta de cimento, desse modo o processo corrosivo é bastante facilitado no caso de pequenas espessuras de cobrimento.

Diante do exposto, este trabalho teve como objetivo a aplicação de uma técnica sistematizada para avaliação in loco, o uso de ensaios expeditos e por fim aplicação da Metodologia GDE/UnB reformulada por Fonseca (2007). A metodologia GDE/UNB consiste estabelecer critérios de quantificação para o grau de deterioração dos elementos isolados e da estrutura como um todo, baseando-se em parâmetros que consideram as manifestações mais frequentes de danos, sua evolução e a influência do meio ambiente em que a estrutura está inserida (CASTRO, 1994). A partir desta metodologia, em 2007 Fonseca propôs sua reformulação com mudanças nos pontos: conceituação de danos, fatores de intensidade associando alguns danos à corrosão e nos fatores de ponderação. Com esta nova metodologia, este estudo de caso se propôs a aplicar esta sistemática em uma inspeção de edificação, próxima a área costeira, para demonstrar quali e quantitativamente que partes do prédio deverão ser priorizadas em sua manutenção.

Por falta de conhecimento da época de desenvolvimento dos projetos estruturais, realizou-se uma comparação da avaliação das estruturas em relação a normatização atual.

\section{METODOLOGIA}

Com o objetivo de avaliar as manifestações patológicas do edifício comercial em questão, o trabalho foi dividido em etapas e é apresentado do fluxograma abaixo: 


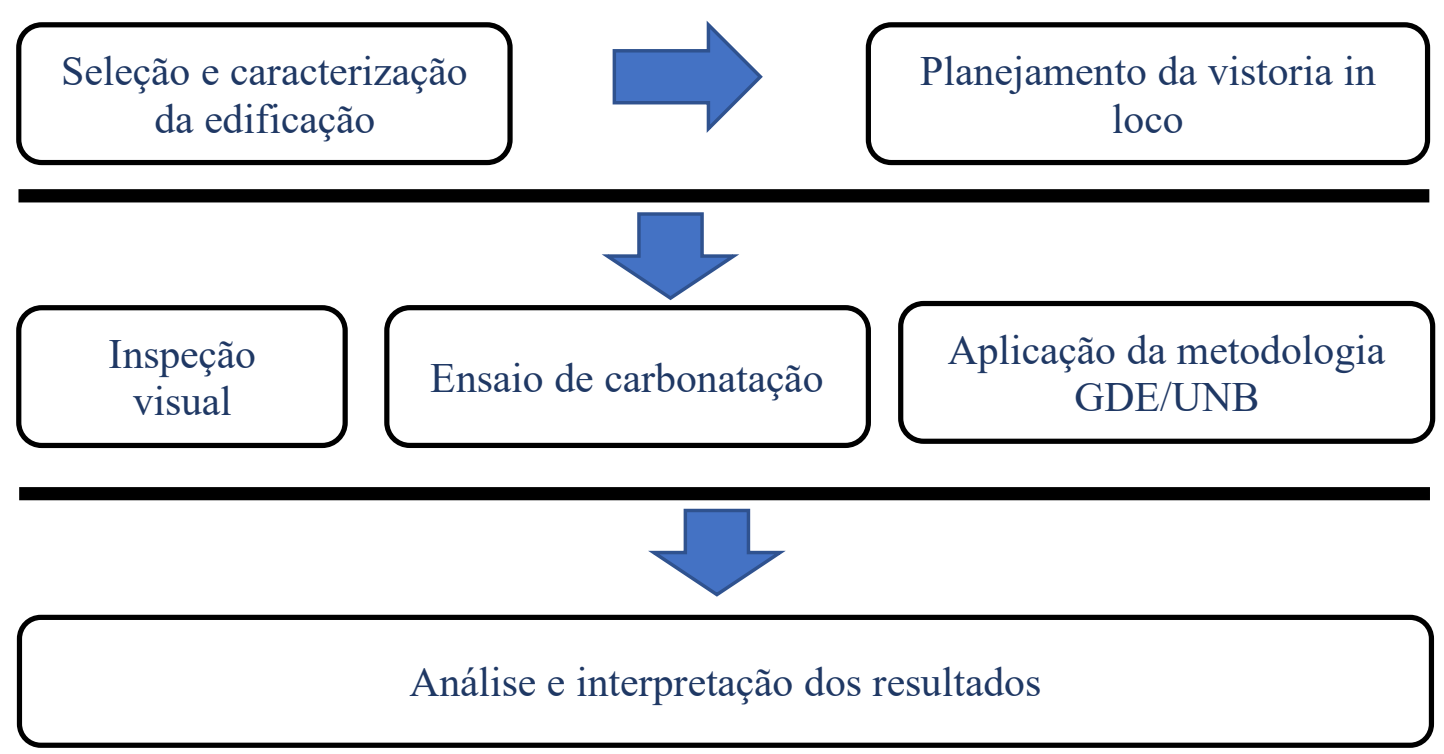

Figura 1 - Fluxograma de metodologia

\subsection{Caracterização do imóvel}

O edifício analisado foi projetado para atender ao uso comercial, mais especificamente no ramo de comercialização de alimentos. Possui cinco pavimentos e fica situado no bairro do Rio Vermelho, na cidade de Salvador-BA.

As análises foram concentradas sobre as manifestações patológicas relacionadas à degradação das estruturas metálicas da cobertura e da estrutura de concreto armado. O prédio está localizado numa região litorânea, que de acordo com a NBR 6118 (2014) pertence a uma zona de agressividade III - ambiente marinho, com alto risco de deterioração da estrutura. A figura 2 apresenta a localização da edificação no bairro e sua imagem em 3 dimensões.

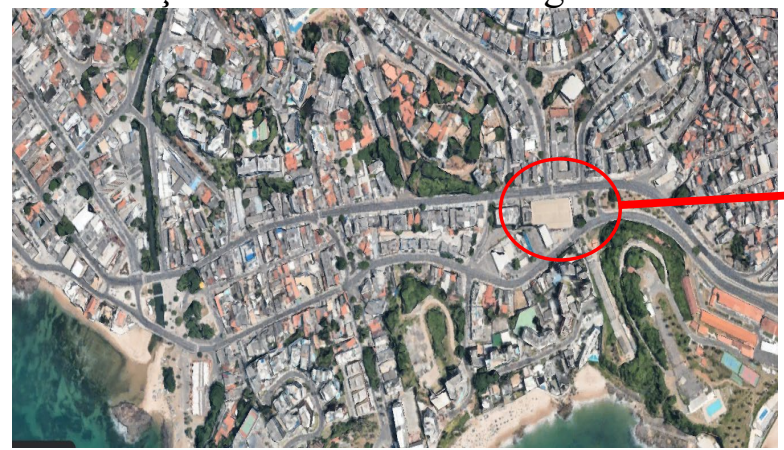

Fonte: Imagem Google Earth (2021)

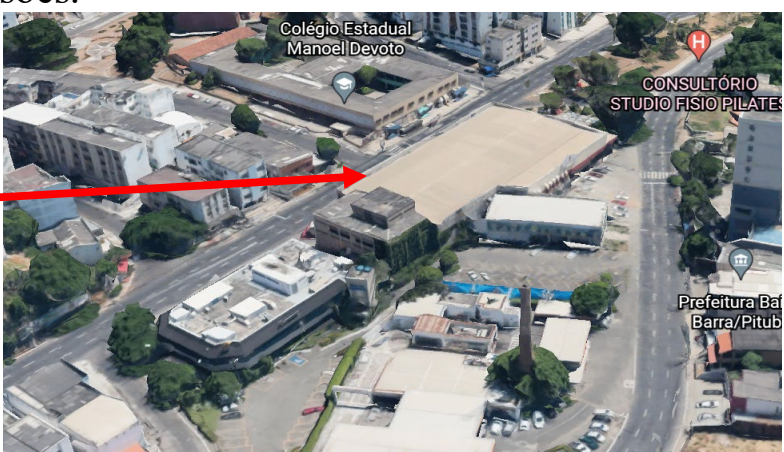

Fonte: Imagem Google Earth (2021)

Figura 2 - Localização da edificação

\subsection{Inspeção visual e ensaio de carbonatação}

A avaliação do imóvel obedeceu a uma análise sistematizada em função da localização das áreas danificadas, com registro fotográfico e medições dos pontos registrados. Foram realizadas medições dimensionais da estrutura, observado que as armaduras estão em processo de corrosão, bem como a alteração do $\mathrm{pH}$ das estruturas de concreto, através da aspersão de solução de fenolftaleína.

\subsection{Aplicação da metodologia GDE/UnB}


O método GDE/UnB foi aplicado na sequência das avaliações realizadas in loco. O método segue o trabalho de Castro (1994), adaptado por Fonseca (2007), e consiste na realização das seguintes etapas: 1) divisão em elementos típicos; 2) adoção do fator de ponderação e atribuir fator de intensidade do dano; 3) cálculo do grau de dano; 4) cálculo do grau de deterioração do elemento; 5) calcular o grau de deterioração da família de elementos; 6) introdução do fator de relevância estrutural da família e cálculo o grau de deterioração da estrutura.

\section{RESULTADOS E DISCUSSÕES}

\subsection{Estrutura metálica da fachada}

A estrutura metálica da fachada está em processo avançado de corrosão (figura 3 a 5) generalizada. Em alguns pontos observou-se que as ligações já foram completamente deterioradas, trazendo riscos de colapso à estrutura (figuras 4 e 5).

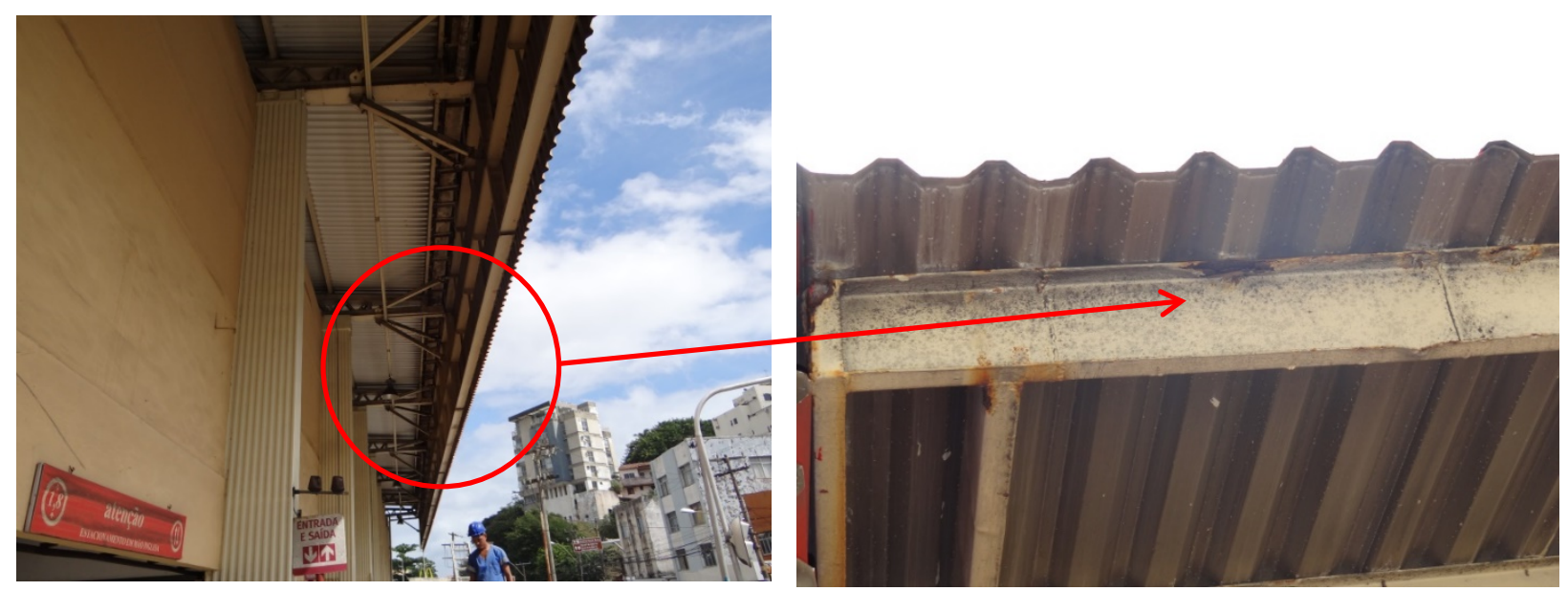

Figura 3 - Vista da estrutura metálica da fachada e Detalhe da corrosão na estrutura metálica da fachada

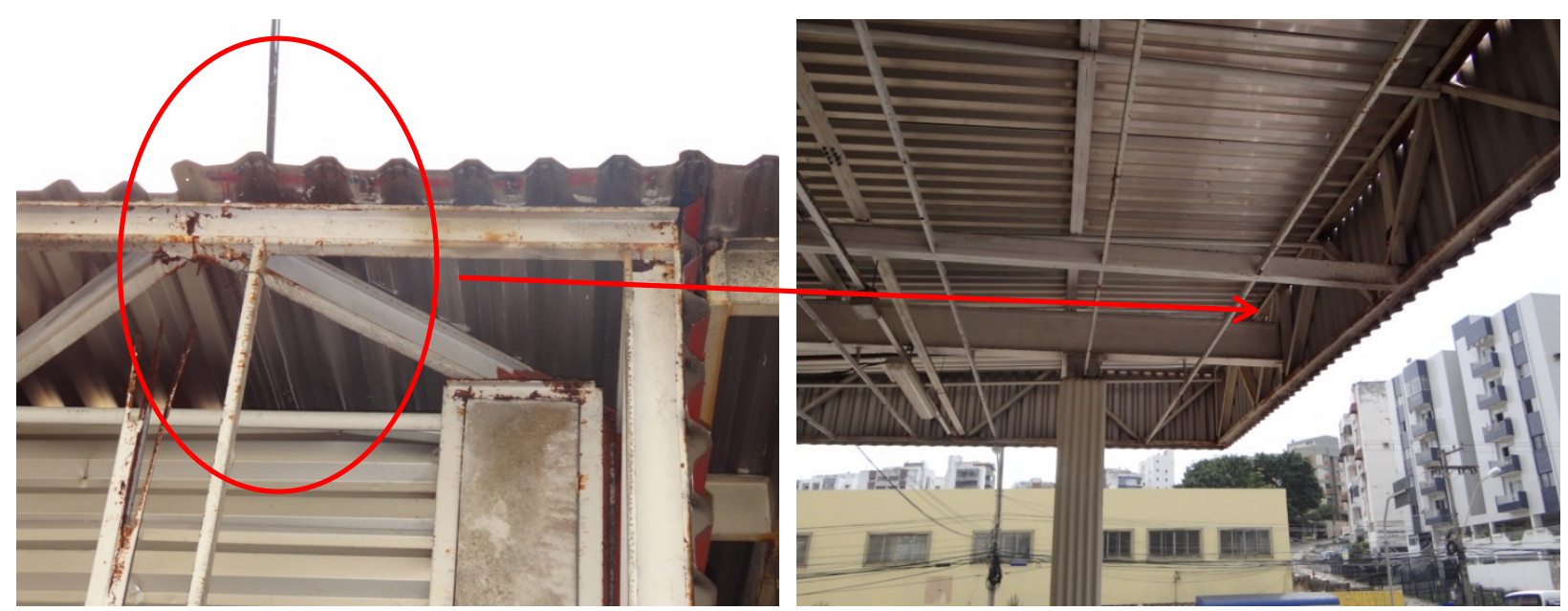

Figura 4 - Detalhe da corrosão na estrutura metálica da fachada e vista interna da corrosão na estrutura metálica da fachada 

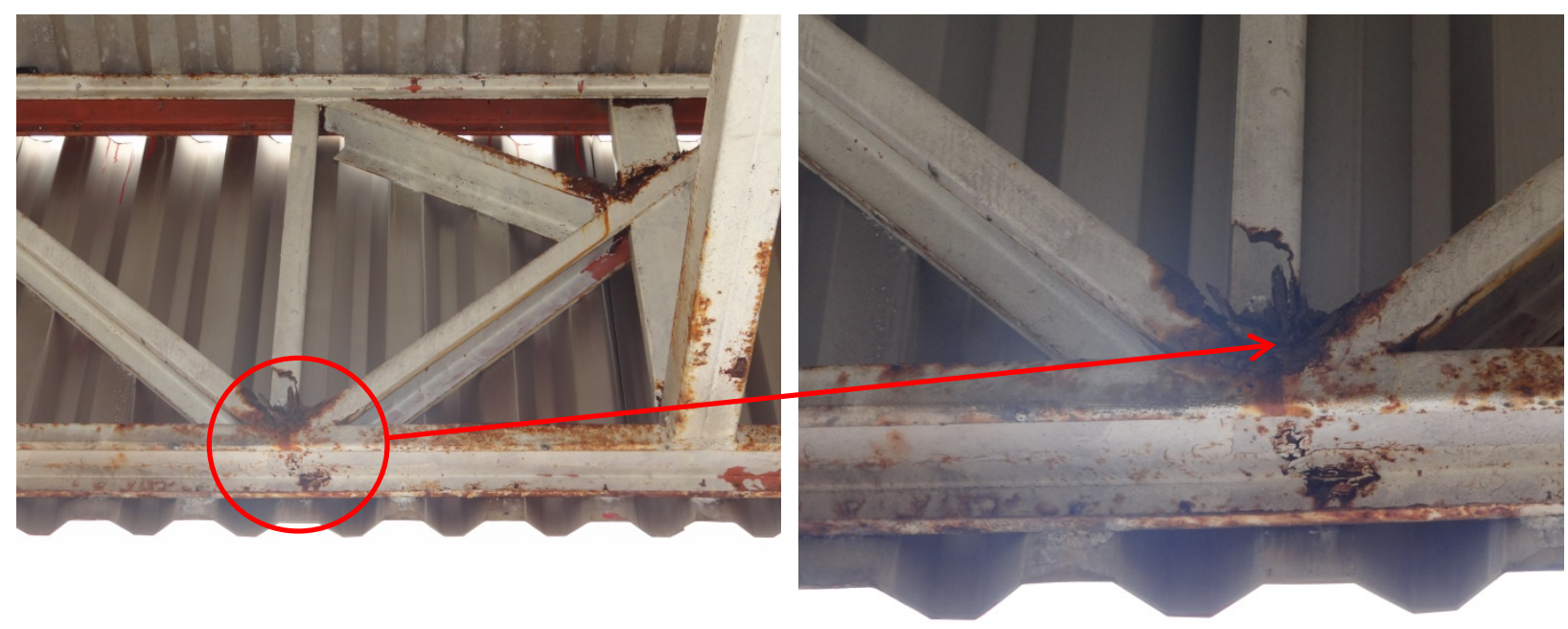

Figura 5 - Vista da corrosão na estrutura metálica da fachada e detalhe da corrosão na estrutura metálica da fachada.

\subsection{Garagem G1}

$\mathrm{Na}$ garagem foram encontradas duas vigas em estado avançado de corrosão, com comprometimento das barras de aço e um pilar (Figura 6 e 7) com as barras de $\phi 8.0 \mathrm{~mm}$ parcialmente corroídas. No primeiro trecho, viga de $15 \times 22 \mathrm{~cm}(1 \times \mathrm{h})$, encontram-se 4 barras de $\phi 10 \mathrm{~mm}$ com estribos de $\phi 5.0 \mathrm{~mm}$ a cada $18 \mathrm{~cm}$. O trecho comprometido compreende 1,10 metros. No segundo trecho, viga de $25 \times 60 \mathrm{~cm}(1 \mathrm{x} \mathrm{h})$, encontram-se 6 barras de $\phi 12.5 \mathrm{~mm}$ com estribos de $\phi 5.0 \mathrm{~mm}$ a cada $21 \mathrm{~cm}$. O trecho comprometido compreende 6 metros. Outro problema encontrado foi a baixa espessura de cobrimento das armaduras da laje (em torno de $5 \mathrm{~mm}$ ). A tabela 7.2 da NBR 6118/2014 estabelece que para edificações situadas em ambientes marinhos o cobrimento mínimo para lajes seja de $35 \mathrm{~mm}$, para garantir a durabilidade da estrutura quanto a penetração de agentes agressivos (cloretos, sulfatos, umidade e oxigênio), bem como proteção contra incêndio.

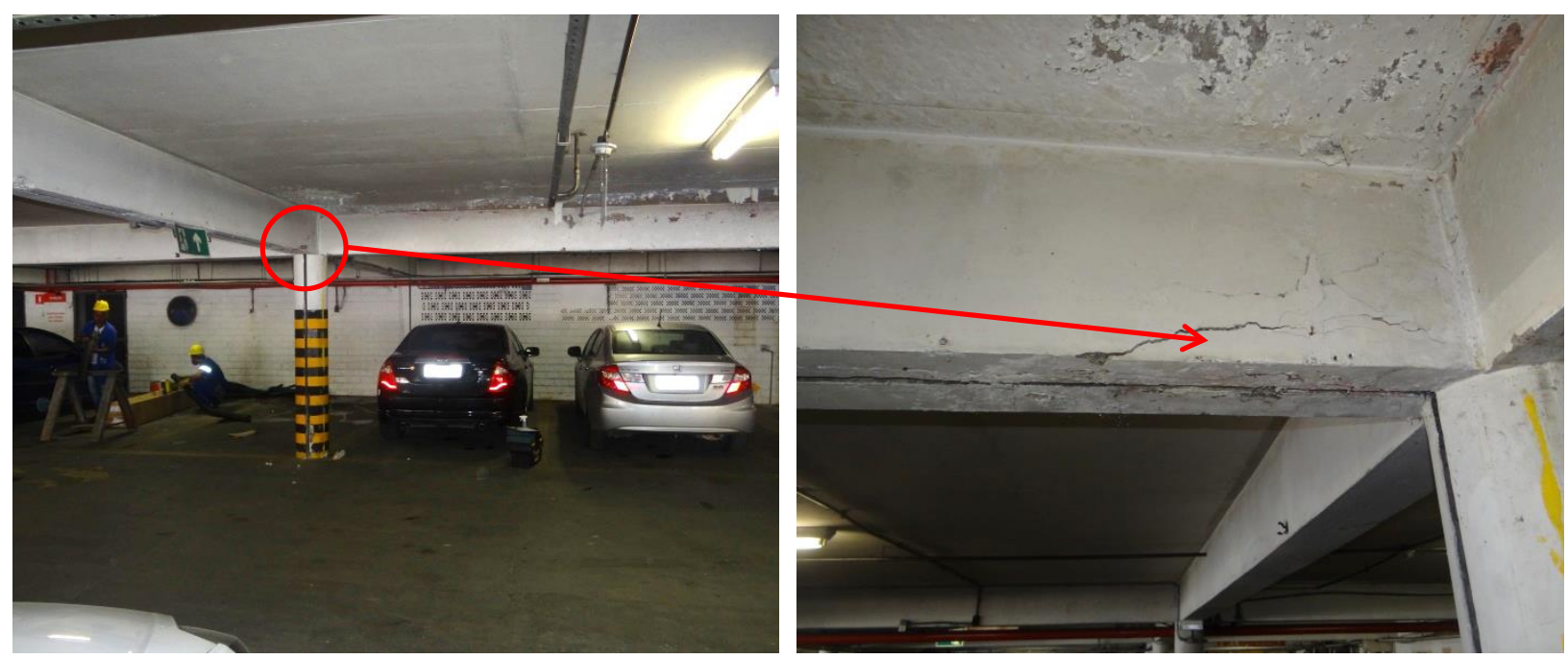

Figura 6 - Vista da viga (trecho 1) em processo de corrosão e detalhe 1 da viga em processo de corrosão. 


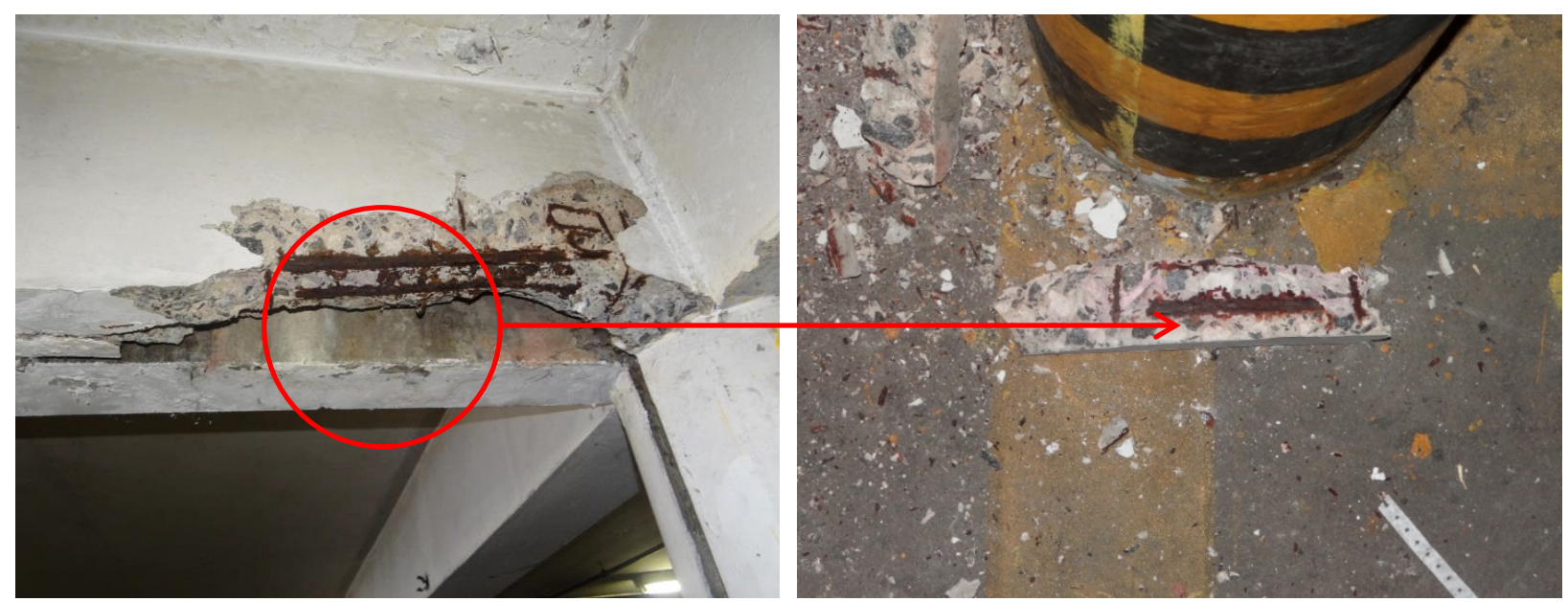

Figura 7 - Detalhe da viga em processo de corrosão e detalhe da seção da viga desplacada no concreto.

A figura 8 mostra o trecho da viga e laje com aspecto róseo a partir da aplicação da fenolfataleína, indicando que, apesar de não haver alteração significativa no $\mathrm{pH}$, há um processo de corrosão em curso, acelerado pela falta de cobrimento adequado nas peças.

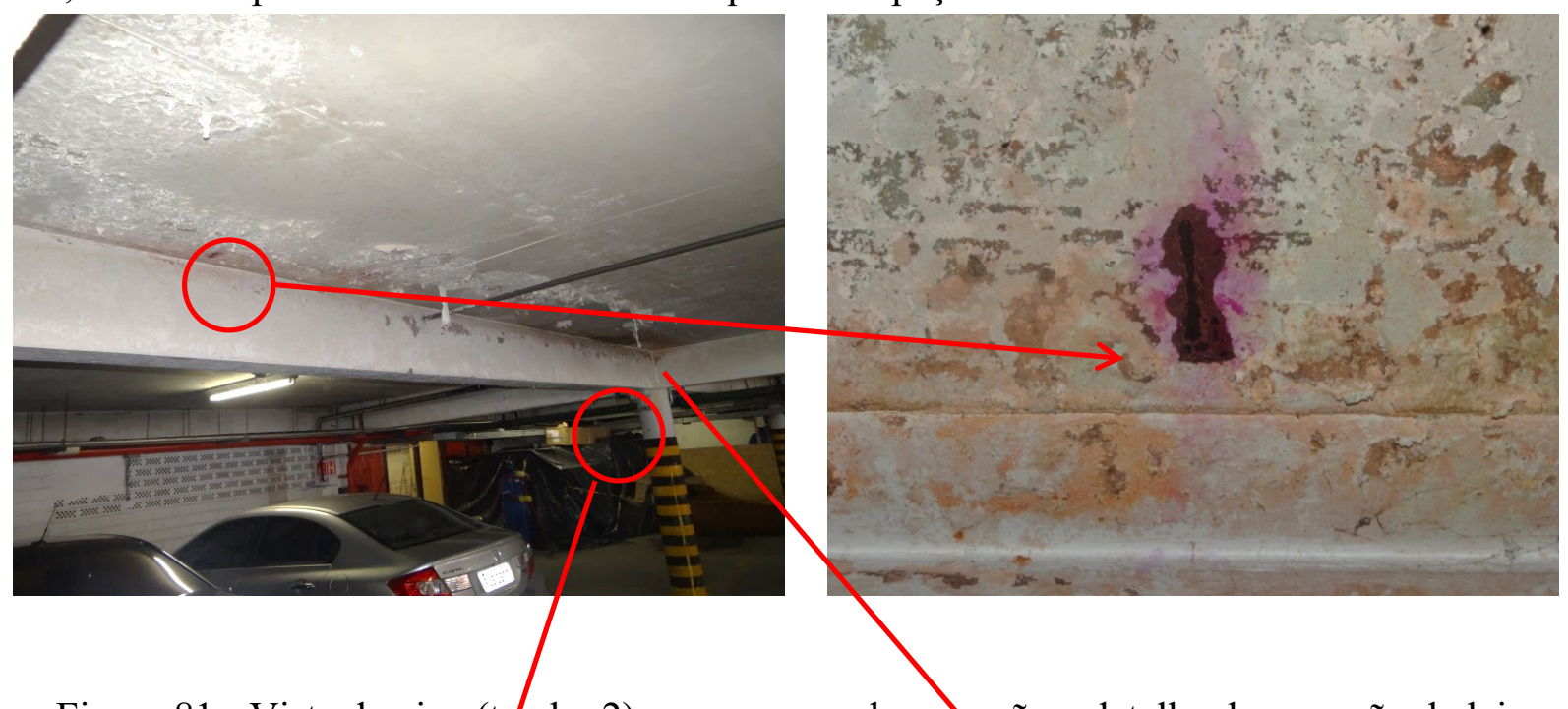

Figura 81 - Vista da viga (trecho 2) em processo de congosão e detalhe da corrosão da laje.
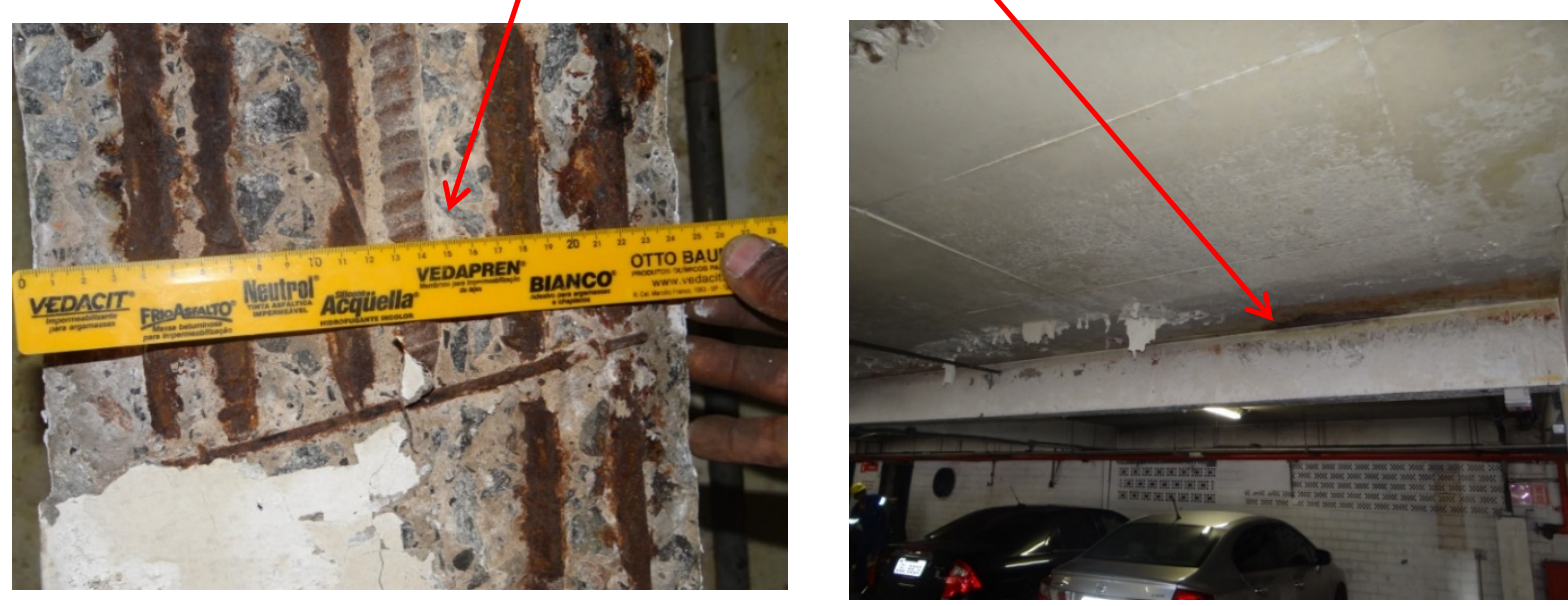

Figura 9 - Detalhe da corrosão da viga (trecho 2) e vista da desfragmentação da pintura da laje. 
Foram encontrados pontos de degradação da pintura de revestimento do teto devido a ação de umidade (Figura 10 e 11), necessitando a recomposição da pintura de proteção da laje.

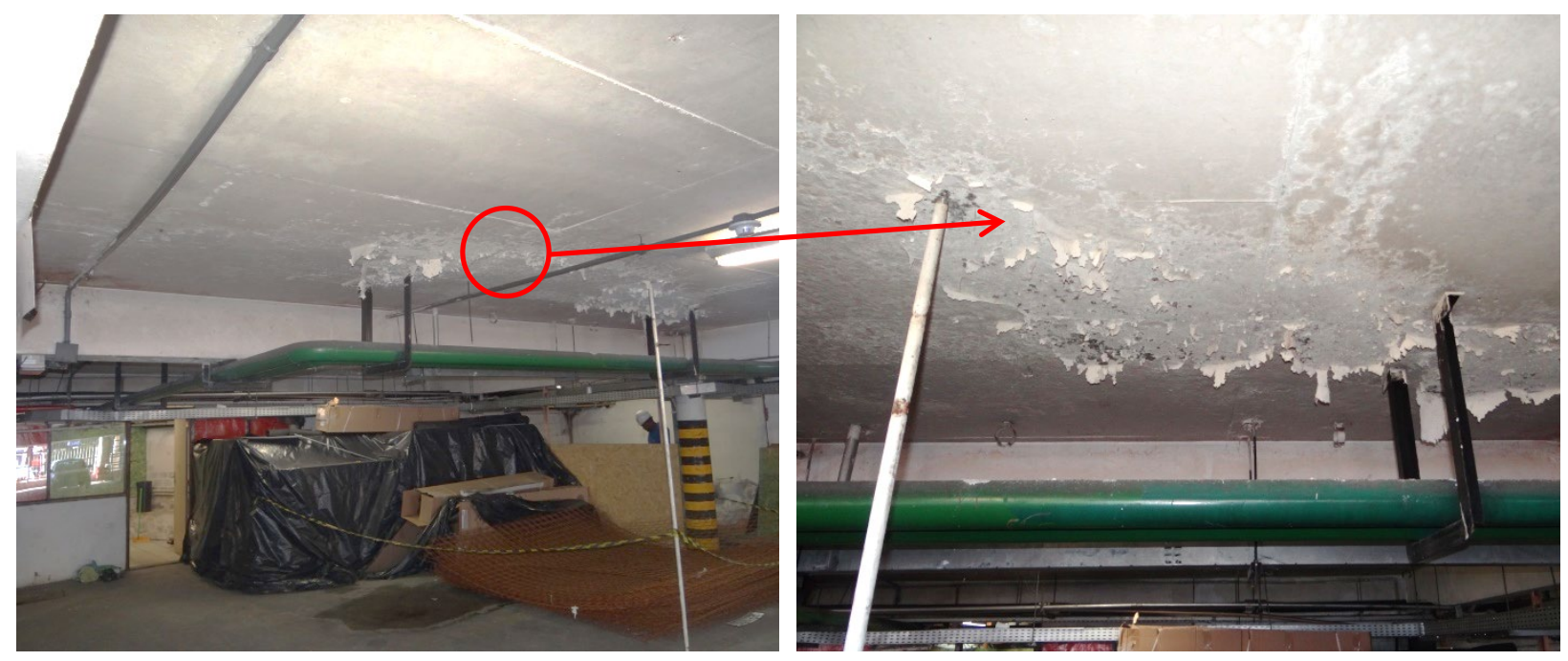

Figura 10 - Detalhe da desfragmentação da pintura da laje (frontal)

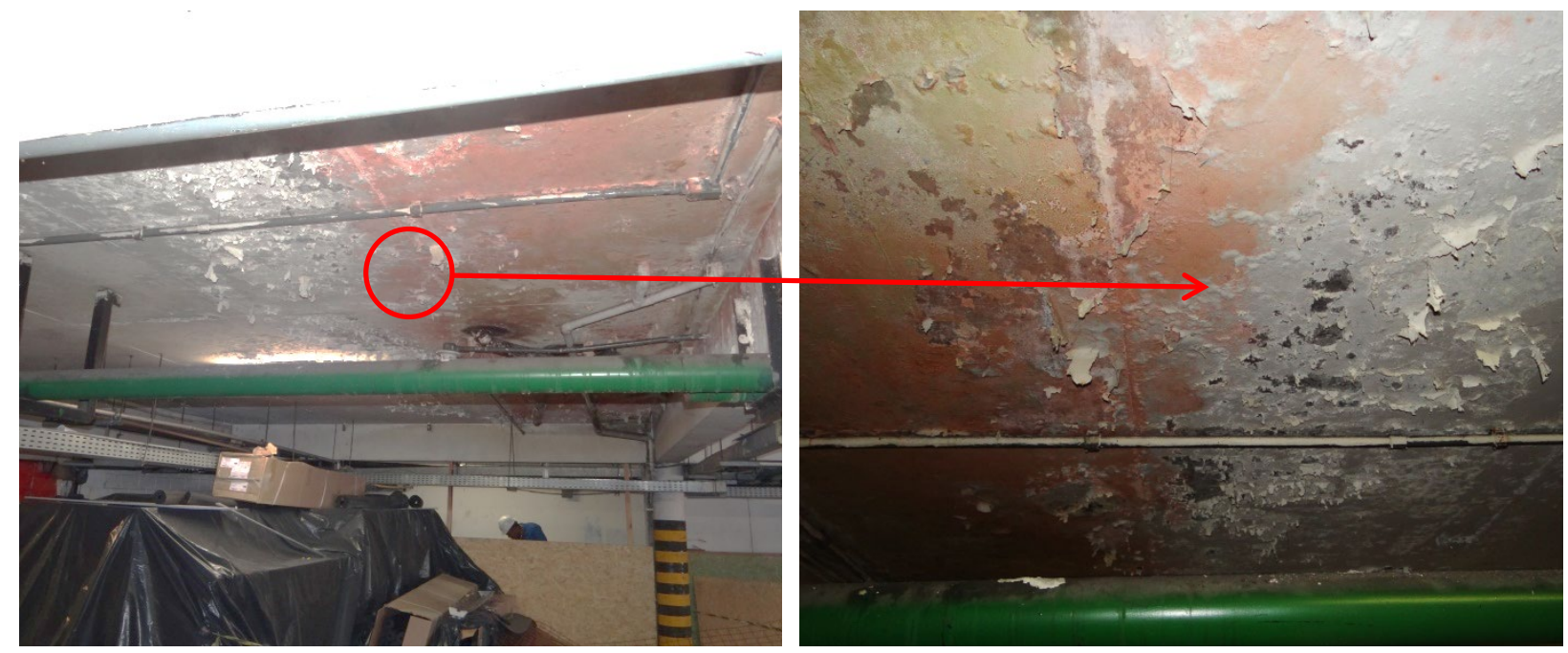

Figura 11 - Detalhe da desfragmentação da pintura da laje (abaixo)

\subsection{Depósito do $2^{\circ}$ andar}

No segundo andar foram encontradas situações de corrosão generalizada nas armaduras das lajes, das quais se destaca:

Sala de embalagem, com extensão de dano numa área de 0,90 x $0,90 \mathrm{~m}$, com cobrimento de 5mm; Trecho 1, com armadura de $\phi 6.3$ com estribos de $\phi 5.0 \mathrm{~mm}$ a cada $10 / 20 \mathrm{~cm}$, o trecho comprometido compreende extensão de $1,20 \mathrm{~m}$ x $1,00 \mathrm{~m}$ e cobrimento de $25 \mathrm{~mm}$, nas quais as barras encontram-se completamente comprometidas, necessitando de substituição; Sala de jogos, com armadura de $\phi 6.3$ com estribos de $\phi 5.0 \mathrm{~mm}$ a cada $10 / 20 \mathrm{~cm}$, o trecho comprometido compreende extensão de $1,50 \mathrm{~m} \times 1,30 \mathrm{~m}$ e cobrimento de $15 \mathrm{~mm}$, nas quais as barras encontram-se completamente comprometidas, necessitando de substituição; Sala de TV, com armadura de $\phi 6.3$ com estribos de $\phi 5.0 \mathrm{~mm}$ a cada $10 / 20 \mathrm{~cm}$, o trecho comprometido compreende extensão de $1,60 \mathrm{~m}$ x 1,30m e cobrimento de $15 \mathrm{~mm}$, nas quais as barras encontram-se completamente comprometidas, necessitando de substituição; Trecho 2, com armadura de $\phi 6.3$ com estribos de $\phi 5.0 \mathrm{~mm}$ a cada $10 / 20 \mathrm{~cm}$ ), o trecho comprometido compreende extensão de $0,90 \mathrm{~m}$ x $0,50 \mathrm{~m}$, cobrimento de $25 \mathrm{~mm}$, nas quais as barras encontram-se completamente comprometidas, necessitando de substituição; 
Piso, desplacamento por corrosão das armaduras, o trecho comprometido compreende extensão de $1,00 \mathrm{~m}$ x $0,60 \mathrm{~m}$ com cobrimento de $20 \mathrm{~mm}$.

Outro problema encontrado foi a baixa espessura de cobrimento das armaduras da laje (variando de 15 a 25mm), ainda seguindo a NBR 6118/2014 estabelece que para edificações situadas em ambientes marinhos o cobrimento mínimo para lajes seja de $35 \mathrm{~mm}$, visando garantir a durabilidade da estrutura quanto a penetração de agentes agressivos (cloretos, sulfatos, umidade e oxigênio) bem como proteção contra incêndio. As figuras 10 e 11 demonstram os efeitos da corrosão e desplacamento das lajes.

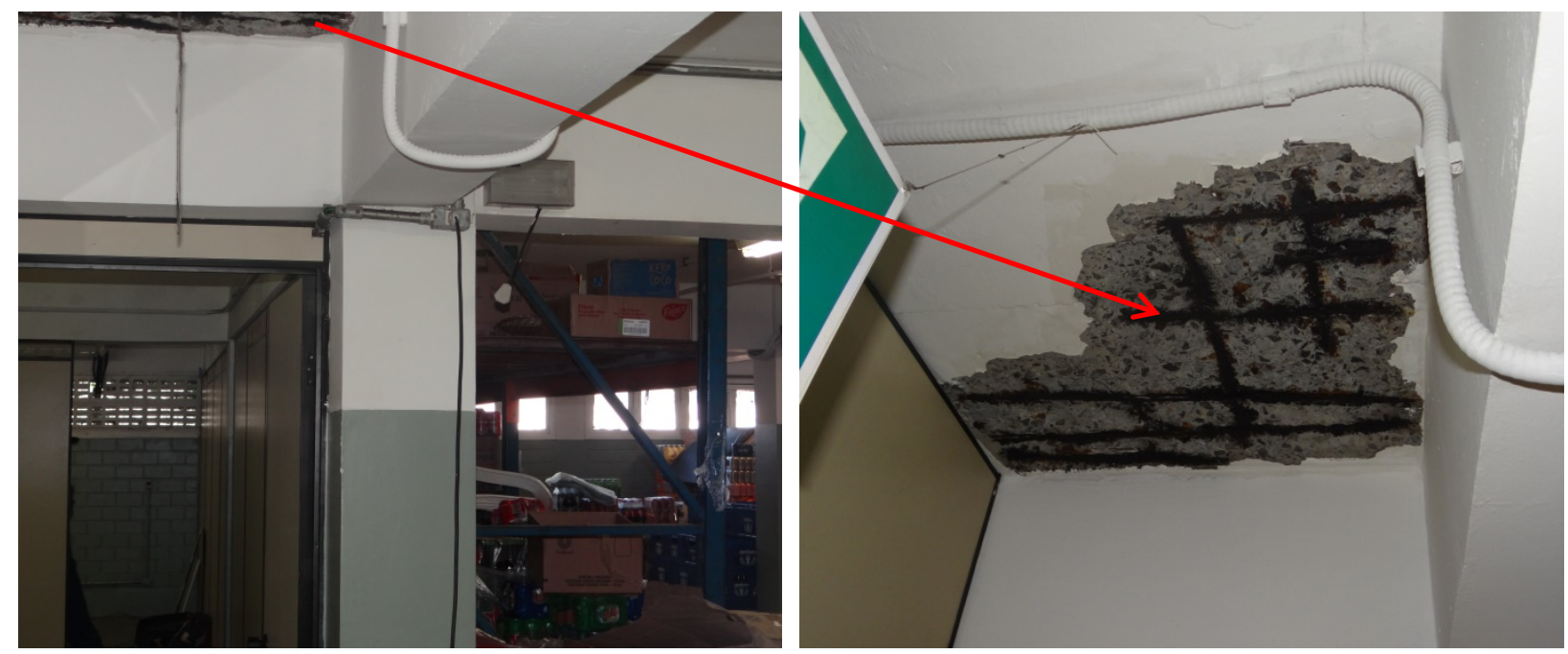

Figura 122 - Vista do processo de corrosão e desplacamento da laje (trecho 1) e detalhe 1 do processo de corrosão e desplacamento da laje.

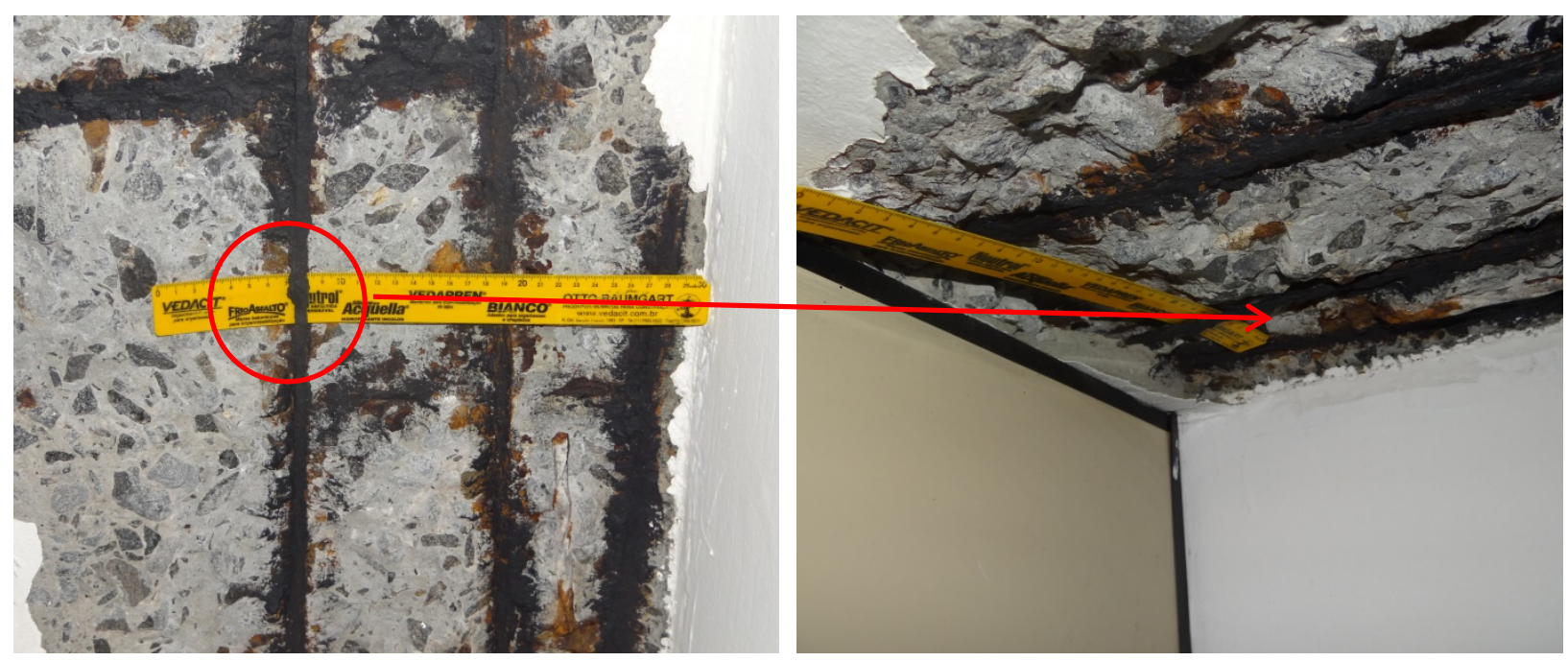

Figura 13 - Detalhe do processo de corrosão e desplacamento da laje e detalhe do processo de

\subsection{Pavimento 3 - Área de exaustores} corrosão e desplacamento da laje.

No terceiro andar foram encontradas situações de corrosão generalizada nas armaduras das lajes, pilares e pisos, espessura da laje de $12 \mathrm{~cm}$, das quais se destaca:

Entrada, corrosão das armaduras com desplacamento do concreto, com extensão de dano numa área de 0,50 x 0,90 m, com cobrimento de 20mm; Trecho 1, com armadura de $\phi 6.3$ com estribos

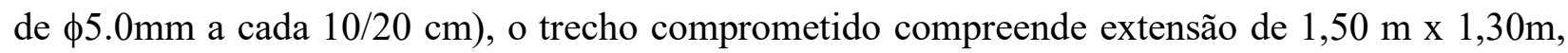
cobrimento de $20 \mathrm{~mm}$, nas quais as barras encontram-se completamente comprometidas, 
necessitando de substituição; Trecho 2, com armadura de $\phi 6.3$ com estribos de $\phi 5.0 \mathrm{~mm}$ a cada $10 / 20 \mathrm{~cm}$ ), o trecho comprometido compreende extensão de $3,80 \mathrm{~m} \mathrm{x} \mathrm{2,10m,} \mathrm{cobrimento} \mathrm{de} \mathrm{20mm,}$ nas quais as barras encontram-se completamente comprometidas, necessitando de substituição; Trecho 3, com armadura de $\phi 6.3$ com estribos de $\phi 5.0 \mathrm{~mm}$ a cada $10 / 20 \mathrm{~cm}$ ), o trecho comprometido compreende extensão de $3,90 \mathrm{~m}$ x 3,20m, cobrimento de $20 \mathrm{~mm}$, nas quais as barras encontram-se completamente comprometidas, necessitando de substituição; Trecho 4, com armadura de $\phi 6.3$ com estribos de $\phi 5.0 \mathrm{~mm}$ a cada $10 / 20 \mathrm{~cm}$ ), o trecho comprometido compreende extensão de $1,20 \mathrm{~m} \times 3,00 \mathrm{~m}$, cobrimento de $20 \mathrm{~mm}$, nas quais as barras encontram-se completamente comprometidas, necessitando de substituição; Trecho 5, com armadura de $\phi 6.3$ com estribos de $\phi 5.0 \mathrm{~mm}$ a cada $10 / 20 \mathrm{~cm}$ ), o trecho comprometido compreende extensão de $2,70 \mathrm{~m}$ x $1,70 \mathrm{~m}$, cobrimento de $20 \mathrm{~mm}$, nas quais as barras encontram-se completamente comprometidas, necessitando de substituição; Trecho 6, com armadura de $\phi 6.3$ com estribos de $\phi 5.0 \mathrm{~mm}$ a cada

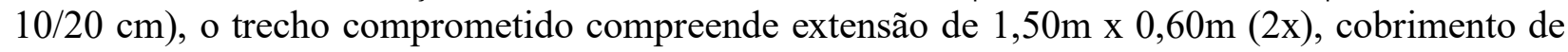
$20 \mathrm{~mm}$, nas quais as barras encontram-se completamente comprometidas, necessitando de substituição; Trecho 7, com armadura de $\phi 6.3$ com estribos de $\phi 5.0 \mathrm{~mm}$ a cada 10/20 cm), a armadura está em processo de corrosão e o concreto desplacado e compreende extensão de $1,50 \mathrm{~m}$ x $1,50 \mathrm{~m}$, cobrimento de $20 \mathrm{~mm}$, não necessita substituição das barras, apenas tratamento anticorrosivo; Trecho 8, com armadura de $\phi 6.3$ com estribos de $\phi 5.0 \mathrm{~mm}$ a cada 10/20 cm), a armadura está em processo de corrosão e o concreto desplacado e compreende extensão de $0,60 \mathrm{~m}$ x $0,90 \mathrm{~m}$, cobrimento de $20 \mathrm{~mm}$, não necessita substituição das barras, apenas tratamento anticorrosivo; Laje, na qual o cobrimento das armaduras é inferior à $5 \mathrm{~mm}$, com armadura de $\phi 6.3$ com estribos de $\phi 5.0 \mathrm{~mm}$ a cada $10 / 20 \mathrm{~cm}$ ), a armadura está em processo de corrosão e o concreto desplacando em alguns.

\subsection{Pavimento 4 - Reservatórios e sala de máquinas dos elevadores}

No terceiro andar foram encontradas situações de corrosão generalizada nas armaduras das lajes, pilares e vigas, além de infiltração no reservatório, das quais se destaca:

Trecho 1, com armadura de $\phi 6.3$ com estribos de $\phi 5.0 \mathrm{~mm}$ a cada $10 / 20 \mathrm{~cm}$ ), o trecho

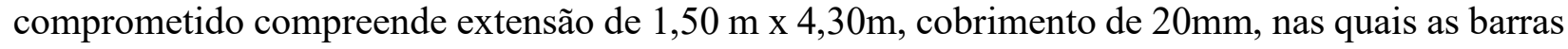
encontram-se completamente comprometidas, necessitando de substituição; Trecho 2, com armadura de $\phi 6.3$ com estribos de $\phi 5.0 \mathrm{~mm}$ a cada $10 / 20 \mathrm{~cm}$ ), o trecho comprometido compreende extensão de $3,70 \mathrm{~m}$ x $0,60 \mathrm{~m}$, cobrimento de $20 \mathrm{~mm}$, nas quais as barras encontram-se completamente comprometidas, necessitando de substituição; Trecho 3, com armadura de $\phi 6.3$ com estribos de $\phi 5.0 \mathrm{~mm}$ a cada $10 / 20 \mathrm{~cm}$ ), o trecho comprometido compreende extensão de $3,60 \mathrm{~m}$ x $0,60 \mathrm{~m}$, cobrimento de $20 \mathrm{~mm}$, nas quais as barras encontram-se completamente comprometidas, necessitando de substituição; Trecho 4, com armadura de $\phi 6.3$ com estribos de $\phi 5.0 \mathrm{~mm}$ a cada $10 / 20 \mathrm{~cm}$ ), o trecho comprometido compreende extensão de $3,50 \mathrm{~m}$ x $0,80 \mathrm{~m}$, cobrimento de $20 \mathrm{~mm}$, nas quais as barras encontram-se completamente comprometidas, necessitando de substituição; Viga, com armadura de $\phi 10.0$ com estribos de $\phi 5.0 \mathrm{~mm}$ a cada $10 / 20 \mathrm{~cm}$ ), o trecho comprometido compreende extensão de $1,20 \mathrm{~m}$, cobrimento de $10 \mathrm{~mm}$, nas quais as barras encontram-se completamente comprometidas, necessitando de substituição; Pilar 1, com armadura de $\phi 10.0$ com estribos de $\phi 5.0 \mathrm{~mm}$ a cada $10 / 20 \mathrm{~cm}$ ), o trecho comprometido compreende extensão de 0,60 , cobrimento de $10 \mathrm{~mm}$, nas quais as barras encontram-se parcialmente comprometidas, necessitando de substituição; Pilar 2, com armadura de $\phi 10.0$ com estribos de $\phi 5.0 \mathrm{~mm}$ a cada $10 / 20 \mathrm{~cm}$ ), a armadura está em processo de corrosão e o concreto desplacado e compreende extensão de 1,30m, cobrimento de $10 \mathrm{~mm}$, nas quais as barras encontram-se parcialmente comprometidas, necessitando de substituição. Infiltração do reservatório foi detectada infiltração com extensa lixiviação do hidróxido de cálcio, o teste com a fenoftaleína mostrou que o vazamento ocorre há muito tempo e 
o problema ainda não foi sanado, conforme a tonalidade rósea encontrada necessitando de serviço urgente de impermeabilização.

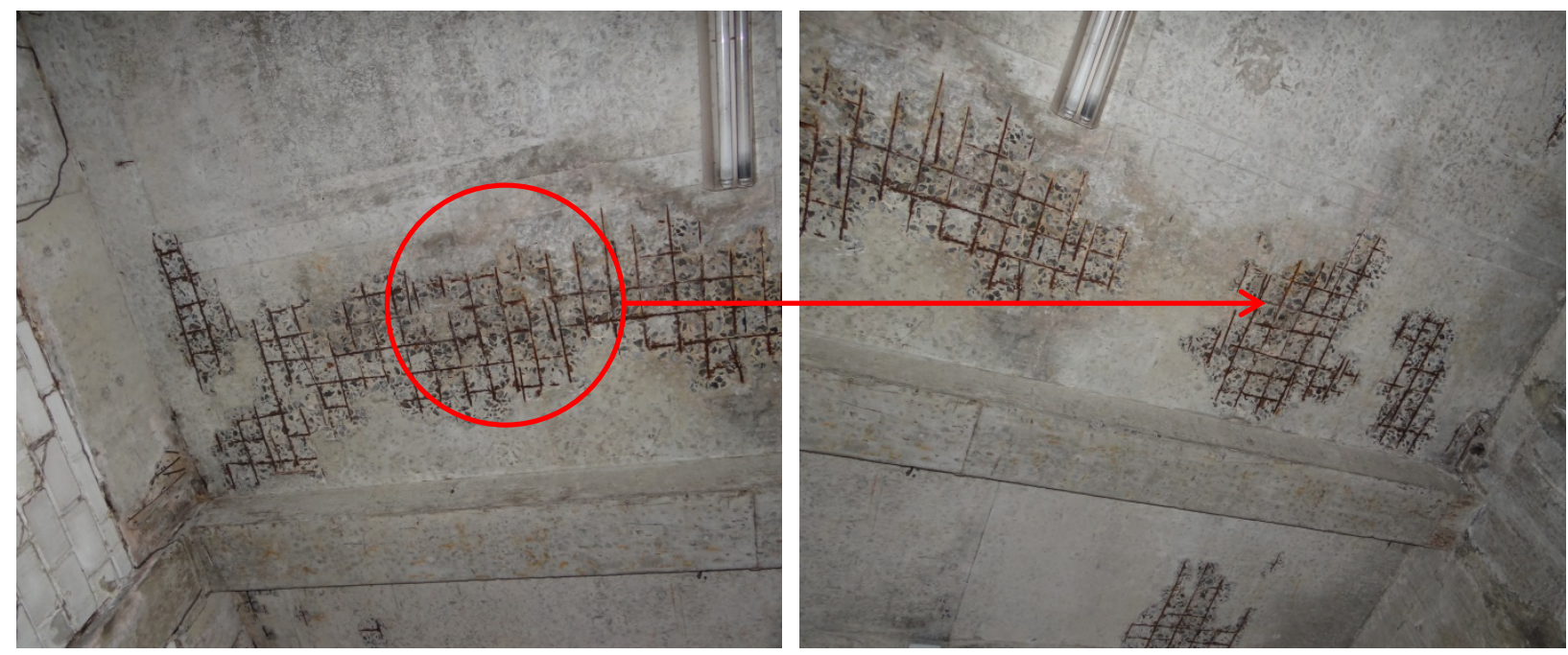

Figura 14 - Detalhe da corrosão da laje (trecho 2) e detalhe da corrosão da laje.

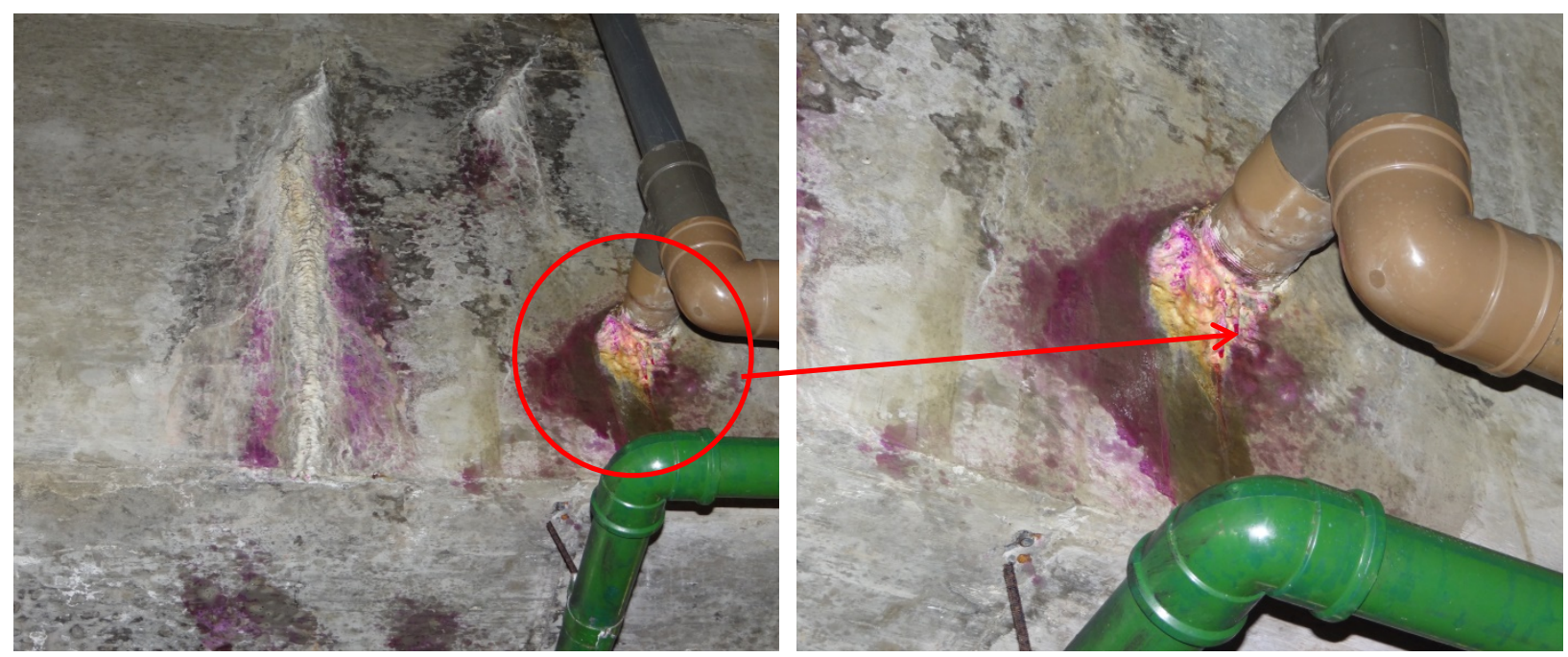

Figura 15 - Detalhe da infiltração no reservatório e detalhe da infiltração no reservatório.

\subsection{Casa de máquinas}

$\mathrm{Na}$ casa de máquinas foi encontrado um problema generalizado de corrosão das armaduras das lajes e alguns pontos em vigas e pilares. 

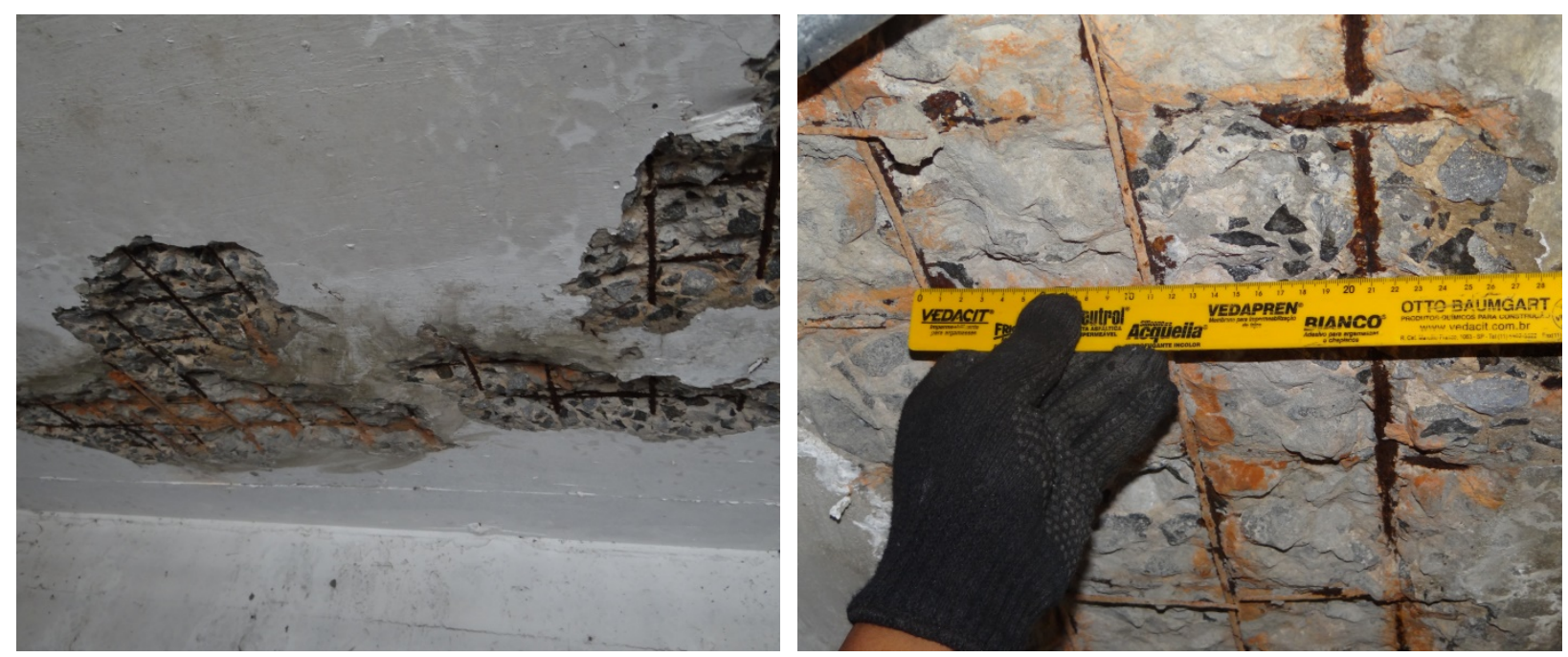

Figura 16 - Detalhe da corrosão na laje e detalhe da corrosão na laje.

\subsection{Metodologia GDE/ UnB}

\subsubsection{Classificação dos danos observados}

A análise realizada constatou que há danos em todas as peças estruturais, principalmente no que tange a corrosão das armaduras. Para realização deste estudo e conforme o caderno de inspeções adotado foram definidos como fator de dano Fp o valor 5 e como fator de intensidade Fi o valor 4 . Todos os pilares apresentaram mais de um tipo de manifestação patológica, com as maiores incidências concentradas em corrosão e cobrimento insuficiente. As falhas mais incidentes neste estudo foram: desagregação de pintura, umidade, desplacamento de concreto, cobrimento insuficiente e corrosão nas armaduras. A partir da separação dos elementos em pilares, vigas e lajes obteve-se como resultados de danos os seguintes gráficos, apresentados nas figuras 17 a 19 , respectivamente pilares, vigas e lajes:

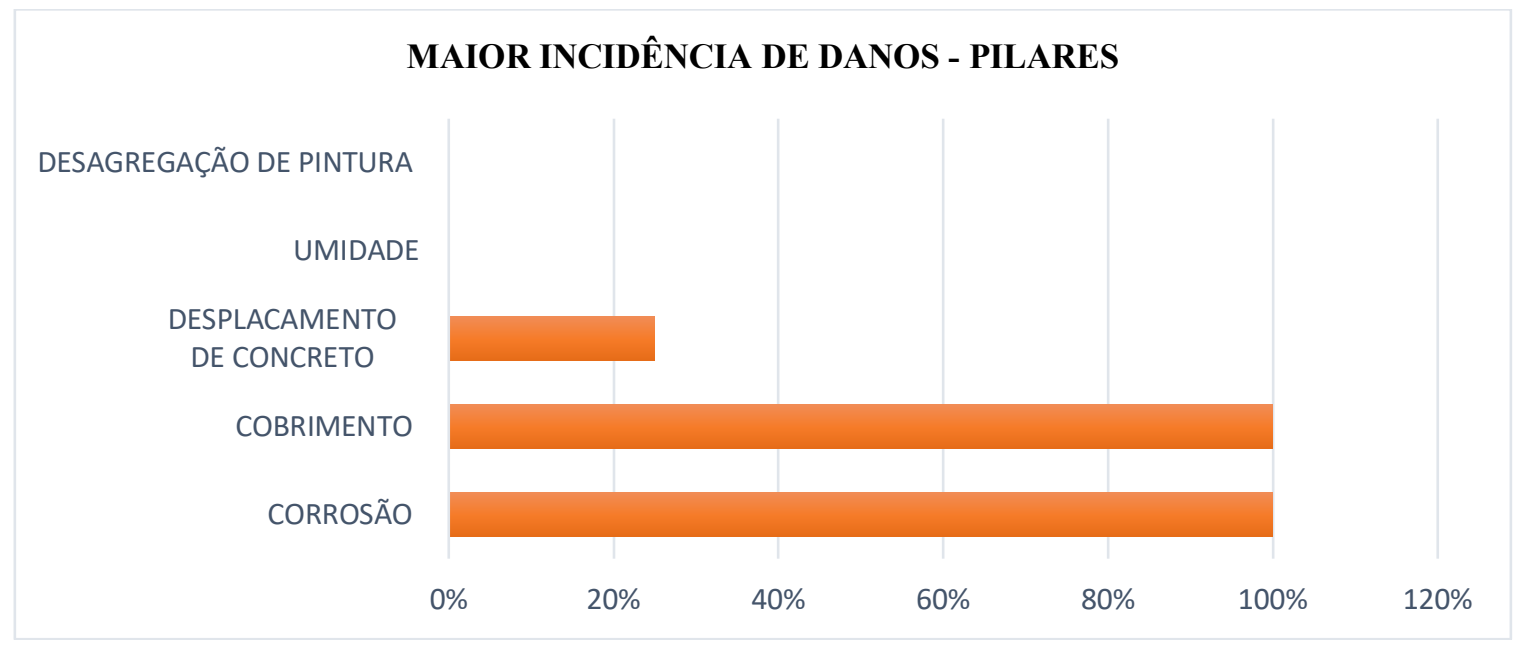

Figura 17 - Principais danos detectados em pilares

Nos elementos de vigas a incidência de manifestações patológicas foram menores e associadas à problemas existentes nas lajes. Foram detectadas muitas ocorrências de desplacamento de concreto, corrosão e cobrimento insuficiente. A figura 18 aponta o percentual de problemas encontrados. 


\section{MAIOR INCIDÊNCIA DE DANOS - VIGAS}

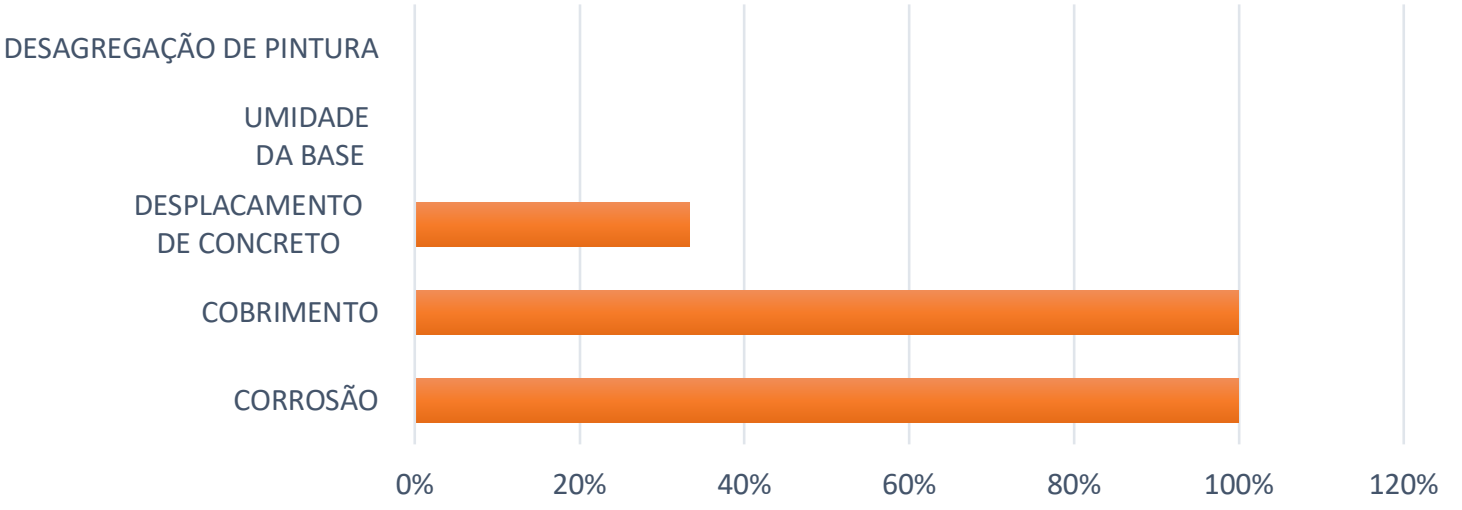

Figura 18 - Principais danos detectados em vigas

No caso das lajes, foram as principais ocorrências detectadas. Além de concentrar os maiores números de patologias ficou evidente que além das condições ambientais (ambiente agressivo) falhas construtivas que resultaram em infiltrações contribuíram na quantidade e nível de degradação (próximo item) demonstrados na inspeção.

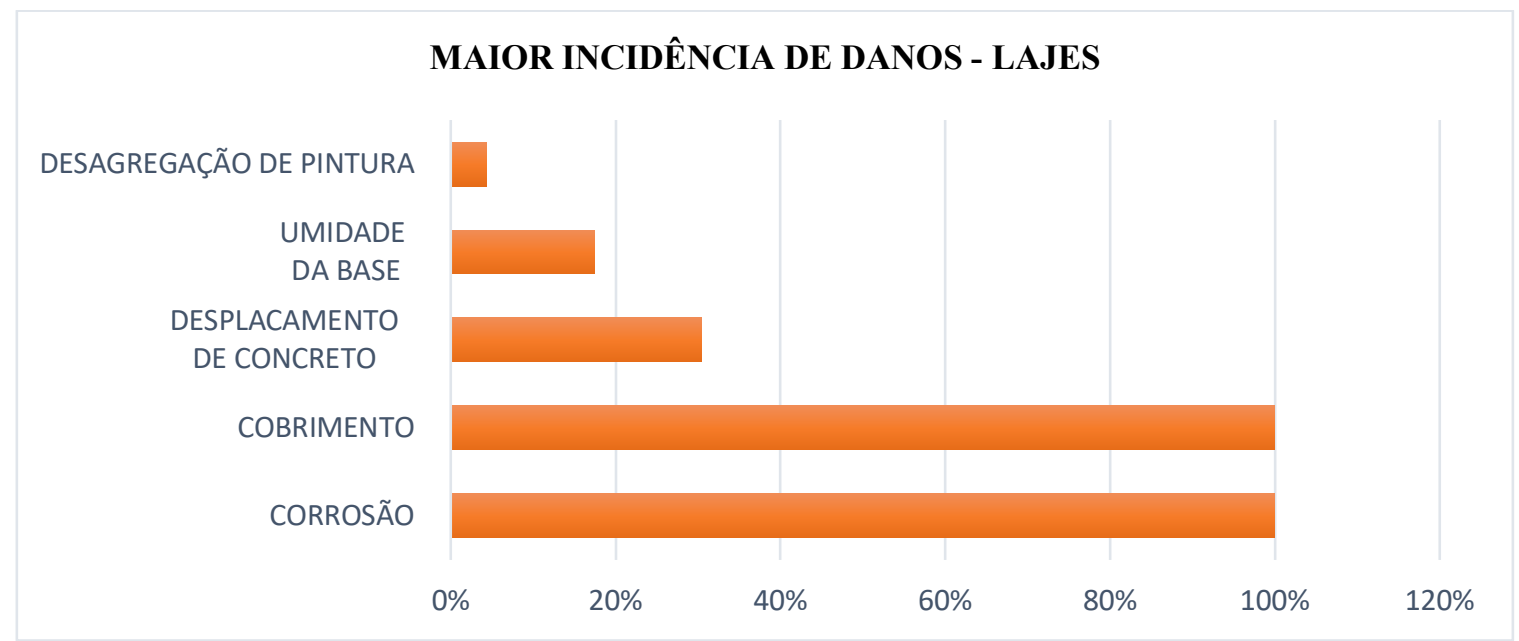

Figura 19 - Principais danos detectados em lajes

\subsubsection{Grau de deterioração dos elementos $-\mathbf{G}_{\mathbf{d e}}$}

Aplicando a análise sob o foco do grau de deterioração dos elementos, temos as seguintes condições:

\begin{tabular}{|l|c|c|c|c|c|}
\hline \multirow{2}{*}{ Elemento } & \multicolumn{5}{|c|}{$\begin{array}{c}\text { Criticidade de lesões } \\
\text { (Percentual) }\end{array}$} \\
\cline { 2 - 7 } & Sem lesões & Leves & Toleráveis & Graves & Crítico \\
\hline Pilares & - & - & - & 57 & 43 \\
\hline Vigas & - & - & - & 33 & 67 \\
\hline Lajes & - & - & - & 57 & 43 \\
\hline
\end{tabular}

Tabela 1 - Grau de deterioração dos elementos 


\subsubsection{Grau de deterioração da estrutura - $\mathbf{G}_{\mathbf{d}}$}

Antes do cálculo para obtenção do grau de deterioração da estrutura é necessário o cálculo da deterioração da família de elementos para então atribuir o fator de relevância estrutural e, por fim, obter-se o $G_{d}$. A tabela 2 mostra os resultados obtidos com os índices finais alcançados.

\begin{tabular}{|l|c|c|c|c|}
\hline \multirow{2}{*}{ Elemento } & \multicolumn{5}{|c|}{ Matriz de cálculos para obtenção do grau de deterioração da } \\
estrutura $\left(\mathrm{G}_{\mathrm{d}}\right)$
\end{tabular}

Tabela 2 - Grau de deterioração dos elementos

Ao final, o grau de classificação geral da estrutura da edificação, seguindo a metodologia de Fonseca (2007), chegou a um grau de criticidade de aproximadamente 48, o qual, segundo a tabela de classificação de deterioração da estrutura adaptada por Fonseca (2007), atingiu o nível alto, devendo-se definir prazo/natureza para inspeção especializada detalhada, além de planejar intervenção em até um ano.

\section{CONCLUSÕES}

A partir dos estudos realizados, constatou-se a ausência de atividades de inspeções prediais e manutenções preventivas periódicas na edificação avaliada. A aplicação da metodologia GDE/UNB apontou, de forma objetiva, as peças degradadas de maneira isolada e, ao final, o que deve ser executado, a partir de um planejamento que determina as prioridades das ações.

Os elementos identificados na inspeção apresentam um grau significativo de deterioração, o que resulta em uma classificação de alta criticidade. Como solução, a própria metodologia recomenda a imediata intervenção com prazo máximo de até um ano, considerando ainda a realização de uma inspeção especializada detalhada.

Fica evidenciado que a realização singular de uma inspeção visual, associada a ensaios expeditos, não gera um plano de intervenção com a priorização dos serviços de manutenção de acordo com o grau de criticidade das anomalias. Desta forma, pode-se afirmar que a associação do método $\mathrm{GDE} / \mathrm{UnB}$ com as avaliações in loco e eventual utilização de ensaios de campo promove maior clareza no processo de identificação e classificação das manifestações patológicas, fornecendo subsídio para a elaboração de planos de intervenção mais assertivos em termos de prazos e prioridades. 


\section{REFERENCIAS}

ABNT - Associação Brasileira de Normas Técnicas (2012). NBR. 5674. Manutenção de edifícios. Rio de Janeiro.

ABNT - Associação Brasileira de Normas Técnicas (2014). NBR. 6118. Projeto de estruturas de concreto - Procedimento. Rio de Janeiro.

BAUER, E.; CASTRO, E. K. ANTUNES, G. R. (2011), "Processo de identificação das manifestações patológicas em fachadas com revestimento cerâmico" in: IX Simpósio Brasileiro de Tecnologia de Argamassas, Belo Horizonte, Minas Gerais.

CASTRO, E. K.(1994). Desenvolvimento de Metodologia para Manutenção de Estruturas de Concreto Armado. Dissertação. Universidade de Brasília. Brasília: DF (BRASIL). p. 129

FONSECA, R.P. (2007). A estrutura do Instituto Central de Ciências: Aspectos históricos, científicos e tecnológicos de projeto, execução, intervenções e propostas de manutenção. Dissertação. Universidade de Brasília. Brasília: DF (BRASIL). p. 213

SILVA, M. N. B. (2014). Avaliação Quantitativa da Degradação e Vida Útil de Revestimentos de Fachada - Aplicação ao Caso de Brasília/DF. Dissertação. Universidade de Brasília. Brasília: DF (BRASIL).

VILASBOAS, J. M. L. (2013). Estudo dos mecanismos de transporte de cloretos no concreto, suas inter-relações e influência na durabilidade de edificações na cidade do Salvador-BA. - Salvador. Dissertação. Universidade Federal da Bahia. Salvador: BA (BRASIL) p. 321 